\title{
Acoustic Monitoring of Migratory Birds over Western Lake Erie: Avian Responses to Barriers and the Importance of Islands
}

\author{
Claire E. SAnders ${ }^{1}$ and Daniel J. Mennill ${ }^{1}$ \\ Department of Biological Sciences, University of Windsor, Windsor Ontario N9B 3P4 Canada \\ ${ }^{1}$ Corresponding authors: sandersc@uwindsor.ca and dmennill@uwindsor.ca
}

Sanders, Claire E., and Daniel J. Mennill. 2014. Acoustic monitoring of migratory birds over western Lake Erie: avian responses to barriers and the importance of islands. Canadian Field-Naturalist 128(2): 135-144.

Understanding the flight patterns of migrating birds is critical for informing conservation actions and management decisions. We studied the geographic and temporal distribution of birds migrating through the southern Great Lakes using nocturnal acoustic monitoring data and banding records from sites on Pelee Island in Lake Erie and on the mainland along the north shore of Lake Erie. Given that Lake Erie may represent an ecological barrier to migratory birds, we predicted that mainland and island sites would show different patterns in both the number of passage migrants and the timing of their migration. Analysis of over 60000 flight calls from $6200 \mathrm{~h}$ of recordings revealed significantly more migrants over the island than the mainland in both spring and fall 2012. The acoustic data provide evidence that none of the species or species groups examined avoided crossing the lake. Birds were detected significantly earlier on Pelee Island than on the north shore of Lake Erie in spring, although they were not detected earlier on the mainland in fall. These results suggest that Lake Erie is not a major barrier to migration. The large number of birds detected over the island suggest that birds may concentrate their flight over islands in the middle of the lake, although recordings of migrants over open water will be required to support this suggestion. Our results show that Pelee Island is an important part of the migratory route of North American birds and provide valuable information on the movement of nocturnal migrants over the Great Lakes.

Key Words: acoustic monitoring; banding; bird migration; ecological barriers; geographic barriers; night-flight calls; Lake Erie; Essex County; Ontario; Pelee Island

\section{Introduction}

Migratory birds can fly non-stop for thousands of kilometres (Egevang et al. 2010; Bairlein et al. 2012; Battley et al. 2012) and are likely to encounter ecological barriers, such as bodies of water, mountain ranges, or stretches of desert as they move between breeding and wintering grounds. Numerous factors might lead birds to select circuitous routes rather than cross over ecological barriers (Alerstam 2001), including their own body condition and external information such as weather conditions (Schmaljohann and Naef-Daenzer 2011). The increased risk of crossing an ecological barrier may be offset by the time or energy saved in using the shortest migratory route (Bruderer 2001). This may be particularly important during spring migration, when urgency drives males to reach their breeding grounds to compete for prime territory and attract mates (Francis and Cooke 1986).

Migration strategies and the behaviour of migrating birds are well-studied areas of ornithology (Moore and Kerlinger 1987; Gauthreaux and Belser 1999). During a journey from Africa to Europe, for example, migratory birds encounter the Sahara Desert, the Mediterranean Sea, and the Alps, all of which could pose a threat to the long-distance migrant. Historically, researchers believed that birds were distributed homogenously as they navigated the Mediterranean (Bruderer 2001); however, banding studies have demonstrated that birds exhibit diverse migration strategies when encountering ecological barriers (Spina and Pilastro 1999). In the Mediter-

ranean, radar studies have shown that the number of migrants over water is often a third to half that over the Iberian Peninsula, demonstrating that most birds prefer to circumnavigate the sea (Bruderer and Liechti 1999). Furthermore, islands and peninsulas appear to play an important role for migrants that choose to cross the Mediterranean Sea, although the use of island stopovers varies among species and within species based on age and sex (Barriocanal and Robson 2007).

The Gulf of Mexico is a major ecological barrier in North America. Birds vary in their propensity to cross the water of this gulf (Stutchbury et al. 2009). For example, geolocator data from a Wood Thrush (Hylocicha mustelina) suggest that it crossed the Gulf of Mexico during its northward migration, but went around on its southward journey; another thrush chose a land-based route on its northward spring migration but then crossed the gulf in the two subsequent spring migrations (Stanley et al. 2012). Barrier islands along the Mississippi coast play an important role for some migrants, providing habitat for foraging before or after the substantial journey across the gulf (Moore et al. 1990).

North America's Great Lakes are ecological obstacles that influence the migration of songbirds (Diehl et al. 2003; Deutschlander and Muheim 2009). The geography of the lakes channels millions of spring and fall migrants through the region. The north and south shores of Lake Erie, as well as the Lake Erie island archipelago, are important stopover locations, and many parts of this region have been designated Important Bird 
Areas by Bird Studies Canada and Nature Canada because of their seasonal concentration of migratory birds (BirdLife International n.d.*). However, because of the technical challenges involved in monitoring nocturnal migration of many bird species, we lack significant information on the ecology and behaviour of migratory birds that pass through the Great Lakes. Recent radar studies in the region have explored ecological barrier avoidance (Diehl et al. 2003), as well as habitat use by migrant birds and stopover ecology (Bonter et al. 2009). Radar data confirm that many migrants cross the Great Lakes in spring and fall, although higher densities of birds were always detected over land than over water during migration (Diehl et al. 2003). Little is known about the importance of the islands in western Lake Erie to migratory bird species.

Although general patterns of barrier avoidance can be revealed through radar studies of migratory birds, it is not possible to distinguish between bird species using radar. In addition, if nocturnal migrants travel at lower altitudes than diurnal migrants, as reported in the Gulf of Mexico, they may not be detected by radar (Farnsworth and Russell 2005). Acoustic monitoring technology overcomes these limitations. Using speciesspecific signatures of the flight calls of migratory birds, we can collect detailed population and behavioural information on cryptic, aquatic, and nocturnal species that are otherwise difficult to monitor (Marques et al. 2013). We recently showed that night-flight call data can be used to determine the timing and magnitude of spring and fall migration through the southern Great Lakes (Sanders and Mennill in press). Therefore, nightflight call data may improve our understanding of the spatial and temporal distribution of avian migration patterns in the western basin of Lake Erie.

In this investigation, we used night-flight call data and banding station records to determine whether Lake Erie acts as an ecological barrier to migratory birds by comparing the number of birds detected on an island mid-way across the lake versus the number detected on the north shore. If Lake Erie acts as an ecological barrier, we expected to find a smaller community of migrants over the island than on the mainland. If Lake Erie does not serve as an ecological barrier, but instead concentrates birds over the island chain as they cross the lake, then we expected to detect more migratory birds over the island than at mainland sites. Finally, if Lake Erie does not serve as a barrier, but an obstacle that temporarily delays the migration of birds, we expected to see a lag in detection between the southerly island and the northerly mainland sites in spring migration, and the reverse pattern in the fall.

\section{Study Area}

We studied bird migration in Essex County, Ontario, during the 2012 spring migration from April 15 to June 15 and the 2012 fall migration from August 15 to November 10 . We recorded night-flight calls at seven loca- tions (Figure 1). Three recording sites were located on Pelee Island mid-way across Lake Erie: two at a bird banding station in Fish Point Provincial Nature Reserve at the southern end of the island $\left(41^{\circ} 44^{\prime} \mathrm{N}, 82^{\circ} 40^{\prime} \mathrm{W}\right)$ and one $15 \mathrm{~km}$ north at Lighthouse Point Provincial Nature Reserve at the northern end of the island $\left(41^{\circ} 47^{\prime} \mathrm{N}\right.$, $82^{\circ} 38^{\prime} \mathrm{W}$ ). Four recording sites were located on the north shore of Lake Erie: Holiday Beach Migration Observatory in the Holiday Beach Conservation Area $\left(42^{\circ} 02^{\prime} \mathrm{N}, 83^{\circ} 02^{\prime} \mathrm{W}\right)$; a private woodlot near McGregor, Ontario $\left(42^{\circ} 06^{\prime} \mathrm{N}, 82^{\circ} 59^{\prime} \mathrm{W}\right)$; Cedar Creek Conservation Area $\left(41^{\circ} 00^{\prime} \mathrm{N}, 82^{\circ} 47^{\prime} \mathrm{W}\right)$; and Point Pelee National Park $\left(41^{\circ} 56^{\prime} \mathrm{N}, 82^{\circ} 30^{\prime} \mathrm{W}\right)$.

\section{Methods}

\section{Acoustic recordings}

At each of the seven recording sites, we deployed an autonomous digital recorder (SM-2 Song Meter, Wildlife Acoustics, Concord, Massachusetts) equipped with a single night-flight call microphone (SMX-NFC, Wildlife Acoustics), mounted on a $30 \times 30 \mathrm{~cm}$ plastic plate to minimize recording of sounds below the microphone. We attached the microphone to a $5.8-\mathrm{m}$ pole that we lashed to a tree or post at the seven recording sites. To minimize interference noise from leaves, insects, and amphibians, we positioned the microphones just above tree height. With seven identical microphones all mounted in similar fashion above the trees, we assumed that each of our seven recorders was equally capable of detecting the night-flight calls of birds passing overhead.

As recommended in eBird's Nocturnal Flight Call Count Protocol (eBird n.d.*), we programmed recorders to begin sampling at astronomical dusk and conclude at astronomical dawn (approximately 70 minutes after sunset to 70 minutes before sunrise), when the sun was more than $18^{\circ}$ below the horizon. Recordings were collected at 44 100-Hz sampling frequency with 16-bit accuracy in WAVE format in 1-h and 59-minute files (1-minute silent intervals between files allowed the recorders to write the recordings to memory cards). Each recorder was visited every 3-5 days to change batteries and collect recordings.

Recordings were processed manually to ensure the greatest possible accuracy in detecting all flight calls, as recommended by Swiston and Mennill (2009). We processed recordings in two stages (for detailed description see Sanders and Mennill in press). Briefly, recordings were first visualized as sound spectrograms using Syrinx-PC sound analysis software (J. Burt, Seattle, Washington) and scanned $30 \mathrm{~s}$ at a time, by a team of 12 volunteer sound analysts (spectral settings: 1024 FFT size, Blackman window). We used the time and frequency cursors in Syrinx-PC to annotate all nightflight calls in our recordings.

During the second stage of processing, we classified the species or species group of as many night flight calls as possible. Using both time and frequency characteristics of the spectrograms of various flight calls 

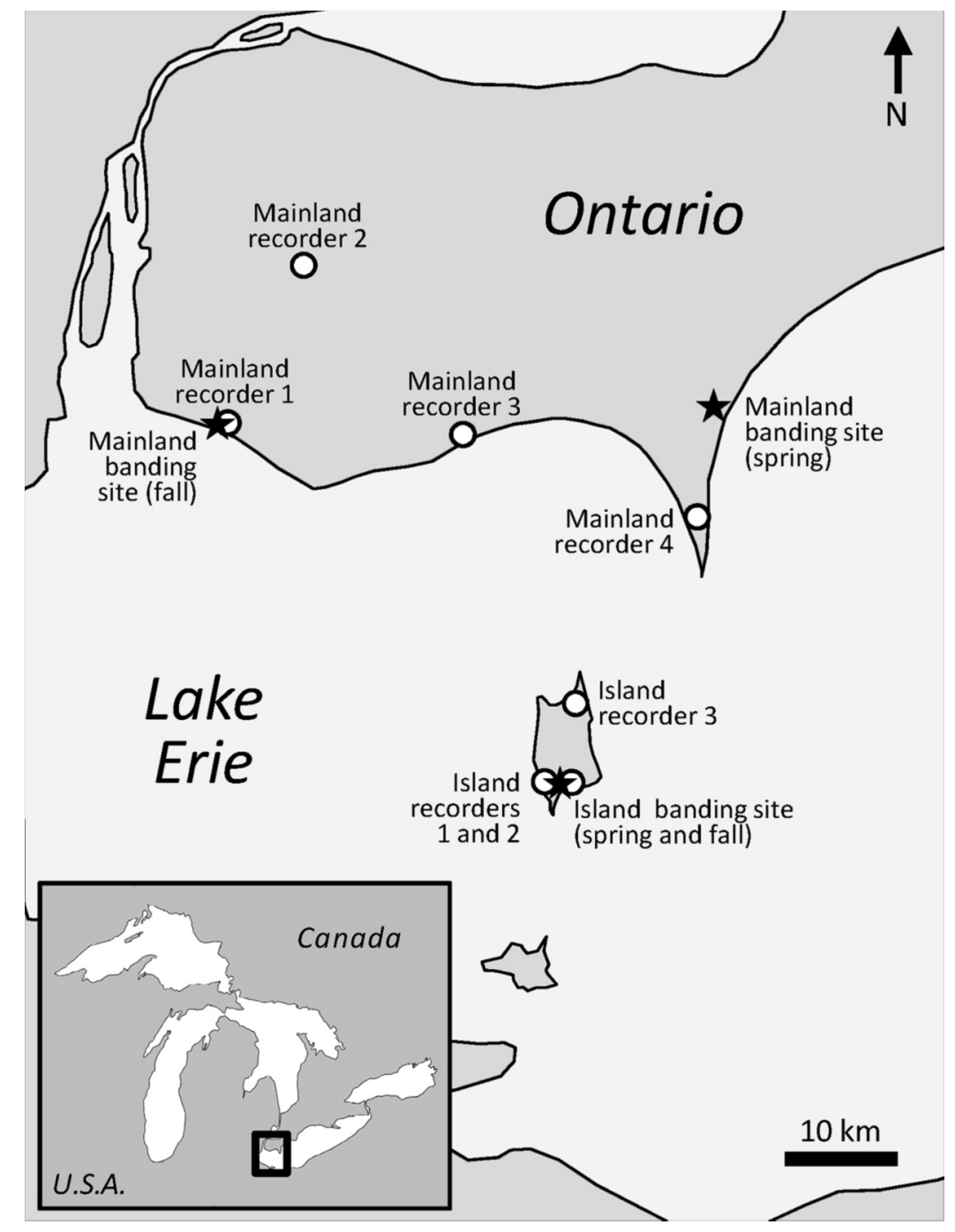

FIGURE 1. Map of study area showing the seven acoustic recording locations (white circles) and the three banding stations (black stars) used to study spring and fall migration in 2012 around the western basin of Lake Erie, Essex County, Ontario.

to distinguish between species (Sanders and Mennill in press, Appendix 1), we constructed a classification chart modified from Evans and Rosenberg (2000). After evaluating our own recorded flight calls and reference recordings (Evans and O'Brien 2002*), we determined that 67 species of nocturnal migrants could be identified to the species level (i.e., their night-flight calls were distinctive) or into seven bioacoustic categories, or species groups, each comprising multiple bird species whose calls could not be distinguished from one another (details in Sanders and Mennill in press, Appendix 1). For example, the night-flight calls of Northern Parula (Setophaga americana) and Pine Warbler (S. pinus) both appear as a single down-sweep on a sound spectrogram; thus, we pooled the detections for these species into the "single down-sweep" speciesgroup category (Sanders and Mennill in press, Appendix 1). Furthermore, several species spanned multiple bioacoustic categories or were classified as distinct at the species level as well as a member of a broader category. For example, Ovenbirds (Seiurus aurocapilla) produce a distinctive checkmark-shaped flight call that is species-specific, but also produce calls that consist only of a frequency modulated upsweep (i.e. the "up" complex; Sanders and Mennill in press).

\section{Banding data}

Banding data were collected at two migration monitoring stations that operated mist nets concurrent with 
our recordings. During spring 2012, birds were banded at Fish Point Provincial Nature Reserve on Pelee Island and at Hillman Marsh Conservation Area on the north shore of Lake Erie from April 15 to June 10. During fall 2012, birds were banded at Fish Point Provincial Nature Reserve on Pelee Island and at Holiday Beach Conservation Area on the north shore of Lake Erie from August 15 to November 10.

The type of species captured in mist nets is heavily influenced by local habitat; the nets at both Pelee Island and Holiday Beach banding stations are located in similar habitats of semi-mature deciduous forest dominated by Silver Maple (Acer saccharinum) and Red Maple (Acer rubrum), with Eastern Cottonwood (Populus deltoides), Black Ash (Fraxinus nigra), American Elm (Ulmus americana), Common Hackberry (Celtis occidentalis), and Pin Oak (Quercus palustris). The Hillman Marsh banding station operates in an early successional habitat previously dominated by hawthorn (Crataegus sp.), Rough-leaved Dogwood (Cornus drummondii), Eastern White Pine (Pinus strobus), Black Cherry (Prunus serotina), Northern Red Oak (Quercus rubra), willow shrubs (Salix sp.), and some Pin Oak (Quercus palustris). The banding station on Pelee Island used 10 mist nets and followed the monitoring protocol recommendations of Hussell and Ralph (2005). The nets at this station were open half an hour before sunrise and ran for $6 \mathrm{~h}$, excluding down time when nets were closed due to bad weather (rain or wind) or high bird volume when nets were closed to ensure safe and efficient bird handling. The Holiday Beach Migration Observatory operated both the banding stations on the mainland at Hillman Marsh and Holiday Beach. As a volunteer organization, this observatory's research efforts varied with the availability of volunteers; seven nets were in use at Hillman Marsh in spring 2012 and 16 at Holiday Beach in fall.

To facilitate comparisons with our acoustic data, we pooled banding records for the species that made up each of our acoustic species groups (e.g. given their similar night-flight calls, we pooled together all Fox Sparrows and Song Sparrows captured in mist nets in a "FOSP/SOSP" species group of bird captures).

\section{Statistical analysis and sample size}

To determine whether there were more detections over the island or the mainland, we combined the detections from all mainland recorders, adjusted for the number of hours per recorder, and calculated the average number of calls per recording station. We repeated this process for the island recorders to produce a relative number of calls per recording station for each species or species group (Table 1). We used sign tests to determine whether the number of acoustic detections over the island was less than the number over the mainland across 38 species and species groups. Given the wellestablished problems of estimating abundance from mist net records (Karr 1981) - especially due to the strong influence of surrounding habitat — we did not compare the total number of birds in mainland and island mist nets.

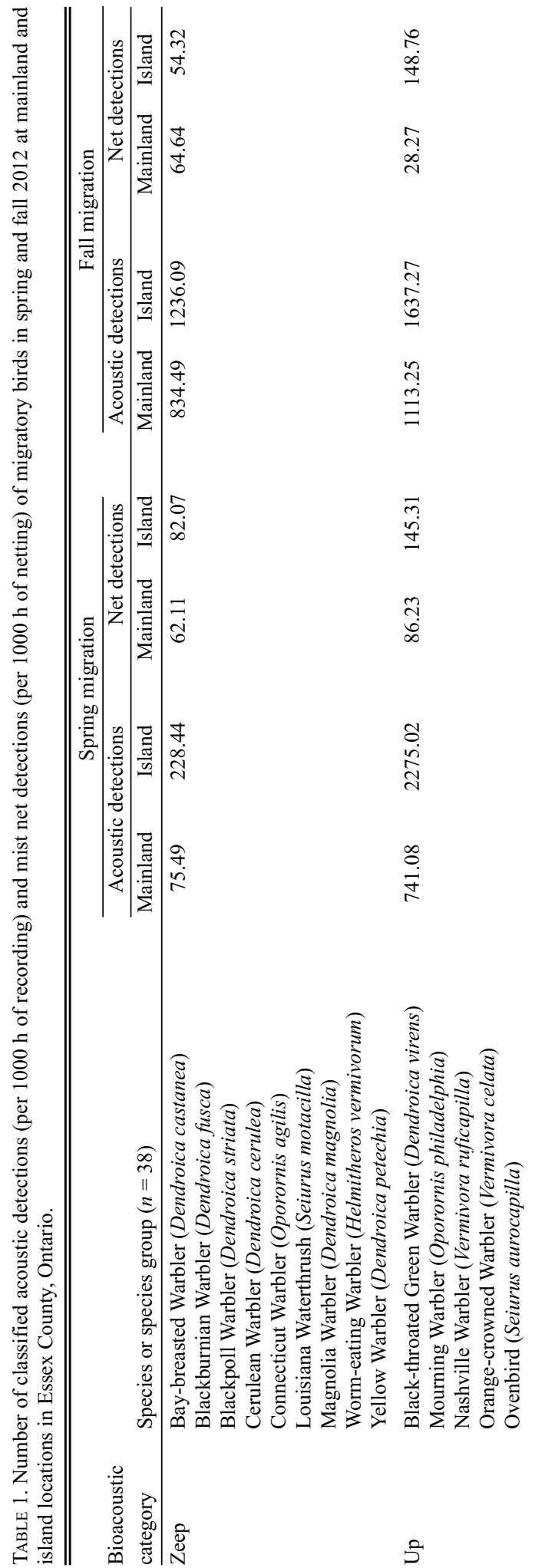




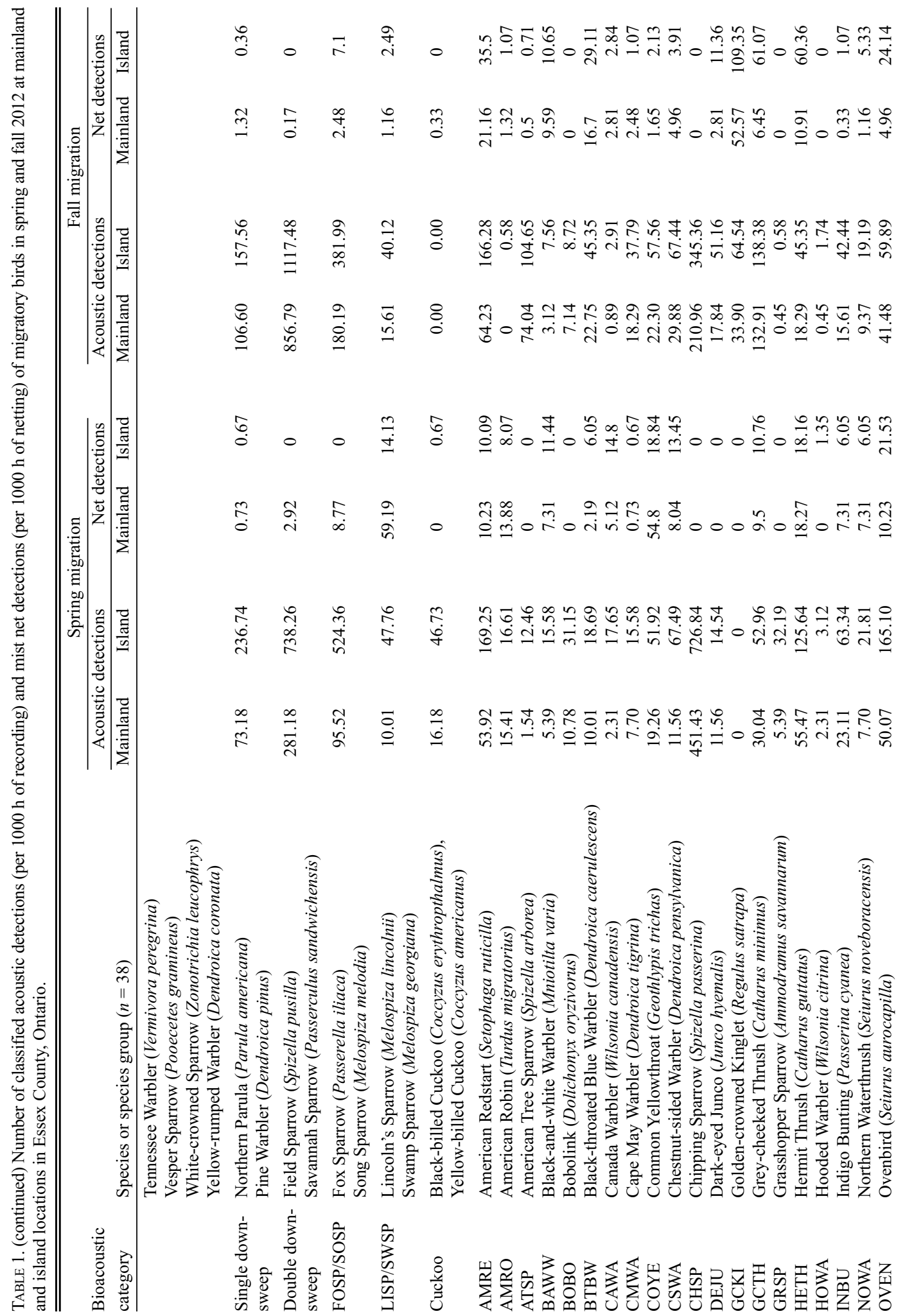




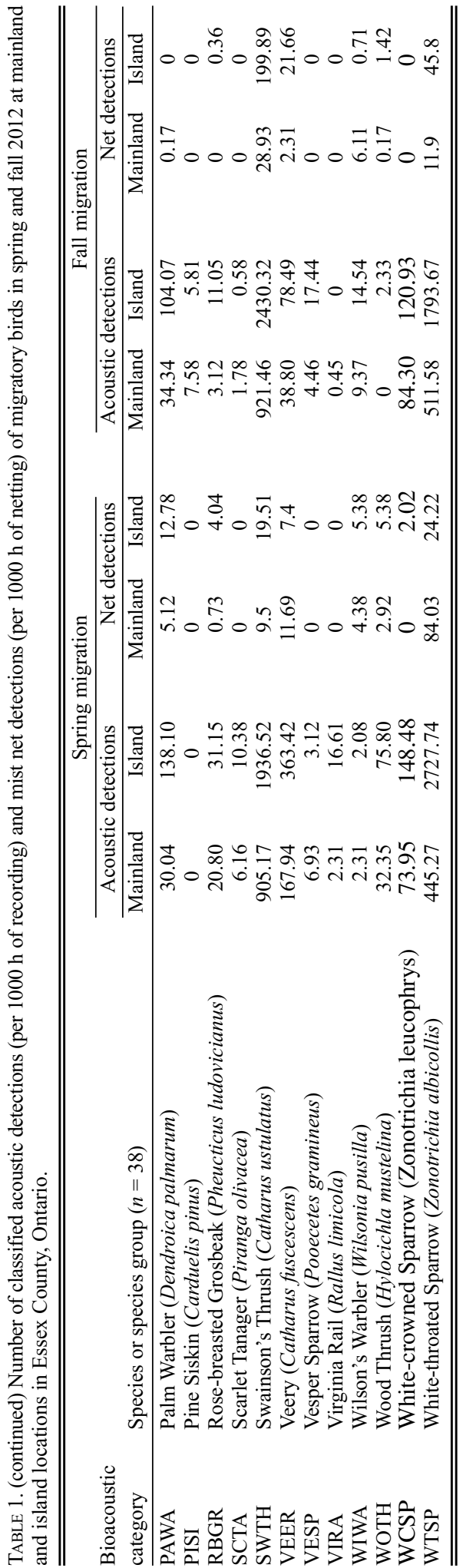

To determine whether some species were present at the mainland sites, but not the island sites, we examined both the acoustic and banding data for the presence or absence of each species or species group in both spring and fall.

To determine whether the date of first detection on the island was different from that on the mainland, we used Wilcoxon sign-rank tests to compare average arrival dates for all species. We pooled the data for the four mainland recorders and calculated the average first detection date for all species or species groups at the mainland sites, and repeated this process for island recorders and sites. We performed a parallel analysis using banding data to compare first arrival dates at the island and mainland banding stations in spring and fall.

\section{Results}

We collected $2261 \mathrm{~h}$ of recordings over 58 nights at the seven recording locations during the spring migration and $3960 \mathrm{~h}$ of recordings over 63 nights at the same locations during the fall migration, for a total of $6237 \mathrm{~h}$ of recordings over both seasons. In these recordings, we noted 60013 nocturnal flight calls: 22554 during spring migration and 37567 during fall migration. We were able to classify, with confidence, 46846 (78\%) calls to species or species group: 16646 (74\%) spring recordings and 30200 (81\%) fall recordings. There was substantial variation in the number of night-flight call detections at the various recording locations in spring and fall (Table 2).

During the spring migration, 834 birds were banded at the island site and 910 birds were banded at the mainland site. During the fall migration, 2079 birds were banded at the island site and 2711 birds were banded at the mainland site.

Number of migrants detected on mainland versus island During spring migration, we detected more nightflight calls on the island than on the mainland (Table 1): 35 species or species groups were more abundant on the island; only two species - Vesper Sparrow (Pooecetes gramineus) and Wilson's Warbler (Wilsonia pusilla) - were more abundant on the mainland (sign test, $P<0.0001, n=37$ ); two of the species indicated in Table 1 were not detected on either the mainland or island recorders in spring: Golden-crowned Kinglet (Regulus satrapa) and Pine Siskin (Carduelis pinus).

Similarly, during fall migration, we also detected more calls on the island than on the mainland (Table 1): 35 species or species groups were more abundant on the island; only three species - Pine Siskin, Scarlet Tanager (Piranga olivacea), and Virginia Rail (Rallus limicola) - were more abundant on the mainland (sign test, $P<0.0001, n=38$; cuckoos were not detected by either mainland or island recorders in fall).

\section{Species detected on mainland versus island}

Acoustic monitoring data revealed that the same composition of species passed over the mainland and 


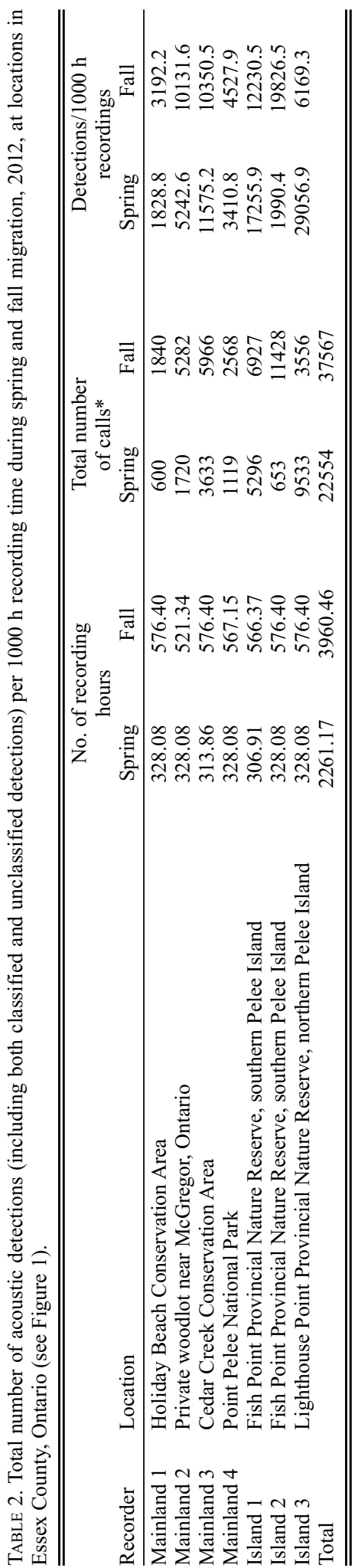

the island (Table 1). We found no evidence in the acoustic recordings that any species avoided crossing Lake Erie. In spring migration, all species or species groups were detected in both mainland and island recordings; in fall migration, American Robin (Turdus migratorius) and Wood Thrush (Hylocichla mustelina) were recorded only on the island, and a single Virginia Rail (Rallus limicola) was recorded on the mainland, with none on the island.

The banding data show a similar pattern in that most species or species groups were captured in both mainland and island mist nets (Table 1). In spring migration, the "double-down" species group and the Fox Sparrow (Passerella iliaca) / Song Sparrow (Melospiza melodia) species group were captured in mainland but not island mist nets, whereas Hooded Warbler (Wilsonia citrina), Mourning Warbler (Oporornis philadelphia), and White-crowned Sparrow (Zonotrichia leucophrys) were captured in island but not mainland mist nets.

In fall migration, the "double down" species group and the Fox Sparrow / Song Sparrow group was captured on the mainland, but not in island mist nets, whereas a Rose-breasted Grosbeak (Pheucticus ludovicianus) was captured on the island but not in the mainland mist nets. Several species (American Robin, Wood Thrush, and the Cuckoos) were netted in spring but not in the fall.

\section{Date of arrival}

In the spring, species were first detected significantly earlier at the island recorders than on the mainland (average ordinal date of first detection on island: $114.1 \pm 1.6$; mainland: $117.1 \pm 1.6$; Wilcoxon sign-rank test: $W=154.5, P=0.0006, n=36$ ). This matched our prediction that birds would be detected earlier at the more southerly site during northward migration. However, in the fall, there was no significant difference between dates of arrival on the mainland and the island (average ordinal date of first detection on island: 254.6 \pm 1.8 ; mainland: $258.1 \pm 2.8$; Wilcoxon sign-rank test: $W=73.5, P=0.09, n=36$ ).

Based on data from the banding stations, we found no significant difference in date of arrival during spring (average ordinal date of first detection on island: 119.8 \pm 1.8 ; mainland: $121.2 \pm 1.9$; Wilcoxon sign-rank test: $W=0.5, P=0.99, n=22$ ) or fall migration (average ordinal date of first detection on island: $248.4 \pm 2.0$; mainland: $252.0 \pm 5.0$; Wilcoxon sign-rank test: $W=$ $36.0, P=0.28, n=25$ ).

\section{Discussion}

Acoustic recordings of nocturnal migrants over western Lake Erie showed that migratory birds do not avoid crossing the lake and suggest that birds may concentrate over Pelee Island mid-way across the lake on both their northward and southward journeys. Island microphones detected significantly more calls in both spring and fall than the microphones located nearby on the 
north shore of Lake Erie. Migrant communities on the mainland and island were similar in composition, although subtle seasonal differences in the relative abundance of each species were evident. Species were detected by acoustic recorders earlier in the spring on the island than on the mainland. Based on the differences in the number of birds and the timing of migration, we conclude that Lake Erie does not represent an ecological barrier to migratory birds. Although our results suggest that a migratory route across Pelee Island is especially important in this region, acoustic recordings collected over the open water of Lake Erie will be required to confirm whether birds concentrate over the island during migration.

Thousands of night-flight call detections revealed a substantially greater number of calls over Pelee Island than over mainland Ontario during both spring and fall migration. This implies that birds use the island archipelago in large numbers during migration. Pelee Island's geography could act to concentrate birds as they approach the north or south tip of the island (Farnsworth 2005). Point Pelee National Park, a peninsula that projects into Lake Erie, may also concentrate birds as they migrate south in the fall (Lincoln et al. 1998*), although our acoustic recorder in the centre of this peninsula (Figure 1) did not detect significantly more migrants than the other mainland sites (Table 2). The theory that peninsulas concentrate migratory birds is supported by the fact that more calls were detected by the microphone at the north end than those at the south end of Pelee Island in spring and the reverse in the fall (Table 2), although this is an anecdotal observation.

We interpret the higher number of acoustic detections over Pelee Island than over the mainland in both seasons as evidence that more migrants pass over the island, but this pattern could also arise if birds increase their calling rate as they pass over islands. Although the function of night-flight calls is still under debate, they may be important in maintaining flock cohesion and communicating directional information to flockmates (Hamilton 1962; Farnsworth 2005). As birds approach a shoreline and detect open water, this may be an especially opportune time to communicate, perhaps to aid orientation among flockmates, leading to higher numbers of flight calls (Farnsworth 2005). However, confirming this pattern requires further investigation at multiple positions, such as microphones mounted in the middle of the lake away from islands, for direct comparison with island recordings. This is a challenging area for future research.

It is also noteworthy that radar research suggests that migrating birds may decrease their altitude as much as $9 \%$ when crossing bodies of water (Bruderer and Liechti 1998); this might make them more likely to be detected by our island microphones than mainland microphones and explain the greater number of calls detected on the island. However, radar data suggest that Great Lake islands are important parts of the migratory flyway (Diehl et al. 2003); thus, these alternative explanations alone cannot account for the higher number of migrants detected on the island.

All songbird species or species groups were detected by the island recorders in both spring and fall, and mist net data contain only subtle differences. This suggests that the lake is not an insurmountable barrier to any of the nocturnal migratory species or species groups that we studied. Previous radar studies demonstrate that nocturnal migrants cross Lake Erie in significant numbers in both spring and fall (Diehl et al. 2003), although they do not reveal which species are crossing the lake. All species and species groups that we could distinguish do indeed cross over Lake Erie in both fall and spring migration. Further research on seasonal variation in migration paths (especially through the use of geolocators; e.g., Stutchbury et al. 2009), as well as multi-year studies that explore annual variation, will provide important insight into the migration of birds through the Great Lakes.

In the spring, the first birds of each species or species group were detected earlier by the Pelee Island recorders than those on the mainland. This matched our expectation and is consistent with the seasonal direction of migration. However, contrary to our expectation, we did not find the reverse pattern during fall migration, when the dates of first detection were not statistically different at the mainland and island sites. Further investigation is required to explore whether this anomaly is due to Lake Erie serving as a temporary barrier to spring migrants, but not to fall migrants. Further examination of the stopover behaviour of birds on Pelee Island might determine whether they are spending a longer time on the island in the spring than in the fall, which might produce the significant delay in detection on the mainland. This idea stands at odds with the general consensus that the spring migration window is shorter, with many species flying faster and stopping for briefer periods (e.g., American Redstart, Setophaga ruticilla; Morris and Glasgow 2001). Furthermore, our banding data showed no significant differences between mainland and island sites in first arrival date in spring and fall.

Although Lake Erie may not be an insurmountable barrier to migrants, poor weather conditions may amplify the risk of crossing open water. Wind strength and direction, visibility, cloud cover, and temperature play a role in determining the intensity of migration events (Elphick 2007; Gagnon et al. 2011). Low cloud cover may concentrate migrants at lower altitudes, resulting in higher acoustic detection rates (Evans and Mellinger 1999). Furthermore, artificial light may cause disorientation and serve to reorient birds in flight toward the island or cause individuals to increase their calling rate (Evans et al. 2007; Poot et al. 2008). Artificial light may have a more pronounced effect under poor or deteriorating weather conditions when stars are obscured by cloud cover (Farnsworth and Russell 2005; Hüppop 
and Hilgerloh 2012). An investigation into the composition of nocturnal migrants detected over Pelee Island on nights preceding and during strong winds or precipitation could lead to a better understanding of which species are most affected by poor weather while navigating the Great Lakes.

In the western basin of Lake Erie, acoustic and banding data suggest that Pelee Island is an important geographic feature for migratory birds. Many individuals of all species passed over the island in spring and fall, with little indication that they avoided crossing Lake Erie, suggesting that islands in the middle of potential geographic barriers are important for migratory birds. Given that many species of North American migrants are in decline, studies that monitor migratory bird behaviour at smaller geographic scales are important for local management and development decisions in regions where birds are known to concentrate seasonally.

\section{Acknowledgements}

We thank M. Watson for assistance in collecting recordings. We thank C. Berek, A. Demarse, K. Drca, R. Gough, C. Lajoie, J. Mahal, A. Mamo, L. Mehdi, B. Poisson, M. Watson, and A. Weinz for assistance with annotating recordings. We thank the Holiday Beach Migration Observatory for their ongoing volunteerbased efforts to study avian migration in southwestern Ontario. We appreciate the work of bird banders on Pelee Island, and we thank the Canadian Wildlife Service of Environment Canada for providing banding data from Pelee Island. We thank the Essex Region Conservation Authority, Ontario Parks, and Parks Canada for access to conservation areas and parks. We thank C. Francis and an anonymous reviewer for comments that improved this manuscript. Support for this study was provided by the Natural Sciences and Engineering Research Council of Canada, the Canada Foundation for Innovation, the Government of Ontario, the University of Windsor, and Caldwell First Nation.

\section{Documents Cited (marked * in text)}

BirdLife International. n.d. Important Bird Areas in Canada. BirdLife International, Bird Studies Canada, and Nature Canada. Available: http://www.ibacanada.ca/images/iba_ canada_dots_800.jpg (accessed 9 Feb 2014).

eBird. n.d. Entering nocturnal flight call counts. Audubon and Cornell Lab of Ornithology. Available: http://ebird.org/cont ent/ebird/about/nfc-count-protocol (accessed $8 \mathrm{Feb} 2014$ ).

Evans W. R., and M. O'Brien. 2002. Flight calls of migratory birds: eastern North American landbirds (CD-ROM). Old Bird, Inc., Ithaca, New York, USA.

Farnsworth, A., and R.W. Russell. 2005. Interactions between migrating birds and offshore oil and gas platforms in the northern Gulf of Mexico: Final Report. U.S. Department of the Interior, Minerals Management Service, Gulf of Mexico OCS Region, New Orleans, Louisiana, USA. OCS Study MMS 2005-009. 348 pages. Available: http:// www.data.boem.gov/PI/PDFImages/ESPIS/2/2955.pdf (accessed 8 Feb 2014).
Farnsworth, A., M. E. Powers, A. E. Klingensmith, and K. Rosenberg. 2008. Migratory bird monitoring using automated acoustic and Internet technologies. Department of Defense Legacy Program. Project 05-245. Available: http: //www.dodpif.org/legacy/05-245-Acoustic-Internet_FS.pdf (accessed 8 Feb 2014).

Farnsworth, A., M. E. Powers, A. E. Klingensmith, and K. Rosenberg. 2009. Migratory bird monitoring using automated acoustic and Internet technologies. Department of Defense Legacy Program. Project 06-245. Available: http: //www.denix.osd.mil/nr/upload/06-245-FS-Migratory-Bird -Monitoring-Using-Automated-Acoustic-and-internet-tech nologies.pdf (accessed 8 Feb 2014).

Farnsworth, A., M. E. Powers, A. E. Klingensmith, and K. Rosenberg. 2012. Migratory bird monitoring using automated acoustic and Internet technologies. Department of Defense Legacy Program. Project 07-245. Available: http:// www.denix.osd.mil/nr/upload/07-245-Migratory-BirdMonitoring-Fact-Sheet.pdf (accessed 8 Feb 2014).

Gage S. H., E. P. Kasten, and W. Joo. 2009. Deployment and application of environmental acoustics for monitoring bird pathways in wind resource areas. Technical report MSU-REAL-09-1, Remote Environmental Assessment Laboratory, Michigan State University, East Lansing, Michigan.

Lincoln, F. C., S. R. Peterson, and J. L. Zimmerman. 1998. Migration of birds. U.S. Department of the Interior, U.S. Fish and Wildlife Service, Washington, D.C. Circular 16. Available: http://www.npwrc.usgs.gov/resource/birds/ migratio/ (accessed 8 Feb 2014).

\section{Literature Cited}

Alerstam, T. 2001. Detours in bird migration. Journal of Theoretical Biology 209: 319-331.

Bairlein, F., D. R. Norris, R. Nagel, M. Bulte, C. C. Voigt, J. W. Fox, D. J. T. Hussell, and H. Schmaljohann. 2012. Cross-hemisphere migration of a 25 g songbird. Biology Letters 8: 505-507.

Barriocanal, C., and D. Robson. 2007. Spring passage of Willow Warbler Phylloscopus trochilus across the western Mediterranean: comparing islands with the mainland. Ardea 95: 91-96.

Battley, P. F., N. Warnock, T. L. Tibbitts, R. E. Gill, T. Piersma, C. J. Hassell, D. C. Douglas, D. M. Mulcahy, B. D. Gartell, R. Schuckard, D. S. Melville, and A. C. Riegen. 2012. Contrasting extreme long-distance migration patterns in bar-tailed godwits Limosa lapponica. Journal of Avian Biology 43: 21-32.

Bonter, D. N., S. A. Gauthreaux, and T. M. Donovan. 2009. Characteristics of important stopover locations for migrating birds: remote sensing with radar in the Great Lakes basin. Conservation Biology 23: 440-448.

Bruderer, B. 2001. Recent studies modifying current views of nocturnal bird migration in the Mediterranean. Avian Ecology and Behaviour 7: 11-25.

Bruderer, B., and F. Liechti. 1998. Flight behaviour of nocturnally migrating birds in coastal areas - crossing or coasting. Journal of Avian Biology 29: 499-507.

Bruderer, B., and F. Liechti. 1999. Bird migration across the Mediterranean. Pages 1983-1999 in International Ornithological Congress, Durban: Symposium. Edited by N. Adams and R. Slowtow. Bird Life South Africa, Johannesburg, South Africa.

Deutschlander, M. E., and R. Muheim. 2009. Fuel reserves affect migratory orientation of thrushes and sparrows both 
before and after crossing an ecological barrier near their breeding grounds. Journal of Avian Biology 40: 85-89.

Diehl, R., H. R. P. Larkin, and J. E. Black. 2003. Radar observations of bird migration over the Great Lakes. Auk 120: 278-290.

Egevang, C., I. J. Stenhouse, R. A. Phillips, A. Petersen, J. W. Fox, and J. R. D. Silk. 2010. Tracking of Arctic terns Sterna paradisaea reveals longest animal migration. Proceedings of the National Academy of Sciences of the United States of America 107: 2078-2081.

Elphick, J. 2007. The Atlas of Bird Migration: Tracing the Great Journeys of the World's Birds. Firefly Books, Buffalo, New York, USA.

Evans, R. and D. K. Mellinger. 1999. Grassland birds in nocturnal migration. Studies in Avian Biology 19: 219-229.

Evans, W. R. and K. V. Rosenberg. 2000. Acoustic monitoring of night-migrating birds: a progress report. Pages 151-159 in Strategies for Bird Conservation: The Partners in Flight Planning Process; proceedings of the 3rd Partners in Flight workshop, October 1-5, 1995, Cape May, New Jersey. Edited by R. Bonney, D. N. Pashley, R. J. Cooper, and L. Niles. Proceedings RMRS-P-16. U.S. Department of Agriculture, Forest Service, Rocky Mountain Research Station, Ogden, Utah, USA.

Evans, W. R., Y. Akashi, N. S. Altman, and A. M. Manville. 2007. Response of night-migrating songbirds in cloud to colored and flashing light. North American Birds 60: 476-488.

Faaborg, J., R. T. Holmes, A. D. Anders, K. L. Bildstein, K. M. Dugger, S. A. Gauthreaux, Jr., and P. Heglund. 2010. Conserving migratory land birds in the New World: Do we know enough? Ecological Applications 20: 398418.

Francis, C. M., and F. Cooke. 1986. Differential timing of spring migration in wood warblers (Parulidae). Auk 103: 548-556.

Farnsworth, A. 2005. Flight calls and their value for future ornithological studies and conservation research. Auk 122: 733-746.

Gagnon, F., J. Ibarzabal, J. L. Savard, P. Vaillancourt, M. Bélisle, and M. Charles. 2011. Weather effects on autumn nocturnal migration of passerines on opposite shores of the St. Lawrence Estuary. Auk 128: 99-112.

Gauthreaux, Jr, S. A., and C. G. Belser. 1999. Bird migration in the region of the Gulf of Mexico. Pages 1931-1947 in Proceedings of the 22nd International Ornithological Congress, Durban. Edited by N. J. Adams and R. H. Slotow. BirdLife South Africa, Johannesburg, South Africa.

Hamilton, W. J. 1962. Evidence concerning the function of nocturnal call notes of migratory birds. Condor 64: 390401.

Hüppop, O., and G. Hilgerloh. 2012. Flight call rates of migrating thrushes: effects of wind conditions, humidity and time of day at an illuminated offshore platform. Journal of Avian Biology 43: 85-90.

Hussell, D. J. T., and C. J. Ralph. 2005. Recommended methods for monitoring change in landbird populations by counting and capturing migrants. North American Bird Bander 30: 6-20.
Karr, J. R. 1980. Surveying birds with mist nets. Pages 62-67 in Estimating Numbers of Terrestrial Birds (Studies in avian biology no. 6). Edited by C. J. Ralph and M. Scott. Cooper Ornithological Society, Norman, Oklahoma, USA. Available: https://sora.unm.edu/sites/default/files/jou rnals/sab/sab_006.pdf (accessed 8 Feb 2014).

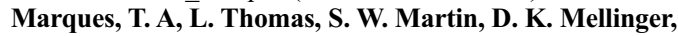
J. A. Ward, D. J. Moretti, D. Harris, and P. Tyack. 2013. Estimating animal population density using passive acoustics. Biological Reviews of the Cambridge Philosophical Society 88: 287-309.

Moore, F. R., and P. Kerlinger. 1987. Stopover and fat deposition by North American wood-warblers (Parulidae) following spring migration over the Gulf of Mexico. Oecologia $74: 47-54$

Moore, F. R., P. Kerlinger, and T. R. Simons. 1990. Stopover on a Gulf Coast barrier island by spring trans-gulf migrants. Wilson Bulletin 102(3): 487-500. Available: http://sora .unm.edu/sites/default/files/journals/wilson/v102n03/p04 87-p0500.pdf (accessed 9 Feb 2014).

Morris, S. R., and J. L. Glasgow. 2001. Comparison of spring and fall migration of American Redstarts on Appledore Island, Maine. Wilson Bulletin 113: 202-210.

Poot, H., B. Ens, and H. De Vries. 2008. Green light for nocturnally migrating birds. Ecology and Society 13: 47.

Sanders, C. E., and D. J. Mennill. In press. Acoustic monitoring of nocturnally migrating birds accurately predicts the timing and magnitude of migration through the Great Lakes. Condor: Ornithological Applications.

Schmaljohann, H., and B. Naef-Daenzer. 2011. Body condition and wind support initiate the shift of migratory direction and timing of nocturnal departure in a songbird. Journal of Animal Ecology 80: 1115-1122.

Sillett, T. S., and R. T. Holmes. 2002. Variation in survivorship of a migratory songbird throughout its annual cycle. Journal of Animal Ecology 71: 296-308.

Spina, F., and A. Pilastro. 1999. Strategy of sea and desert crossing in spring passerine migrants as suggested by the analysis of intra- and inter-specific variation of residual fat levels. Pages 1931-1947 in Proceedings of the 22nd International Ornithological Congress, Durban. Edited by N. J. Adams and R. H. Slotow. BirdLife South Africa, Johannesburg, South Africa.

Stanley, C. Q., M. MacPherson, K. C. Fraser, E. A. McKinnon, and B. J. M. Stutchbury. 2012. Repeat tracking of individual songbirds reveals consistent migration timing but flexibility in route. PloS One 7: e40688.

Stutchbury, B. J. M., S. A. Tarof, T. Done, E. Gow, P. M. Kramer, J. Tautin, J. W. Fox, and V. Afanasyev. 2009. Tracking long-distance songbird migration by using geolocators. Science 323(5916): 896.

Swiston, K. A., and D. J. Mennill. 2009. Comparison of manual and automated cross-correlation methods for identifying target sounds in continuous audio recordings of Pileated, Pale-billed, and putative Ivory-billed Woodpeckers. Journal of Field Ornithology 80: 42-50.

Received 7 October 2013

Accepted 20 November 2013 